\title{
PLANETARY NEBULAE
}

Edited by YERVANT TERZIAN
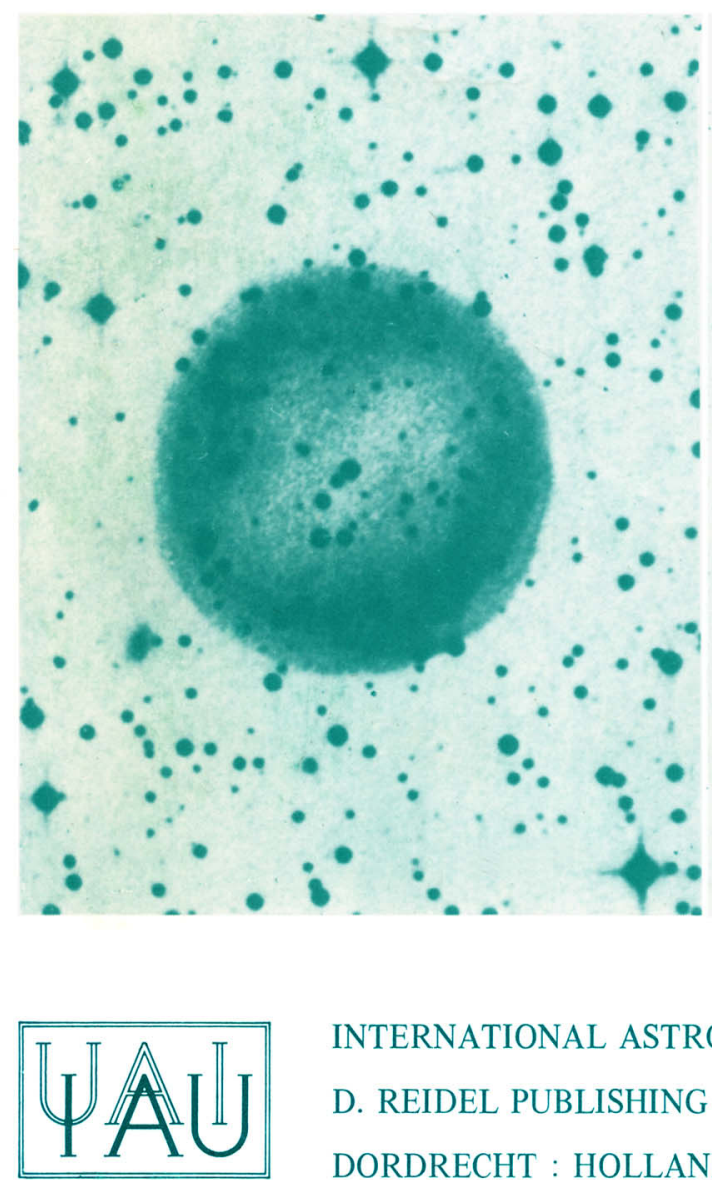

INTERNATIONAL ASTRONOMICAL UNION

D. REIDEL PUBLISHING COMPANY

DORDRECHT : HOLLAND / BOSTON : U.S.A. 


\section{PLANETARY NEBULAE}

Observations and Theory

SYMPOSIUM No. 76

Planetary Nebulae have recently been understood as a normal avenue of the late stages of stellar evolution for a wide range of stellar masses. The nebulae result from the expulsion of the outermost parts of red giant or supergiant stars. Significant progress in recent years includes ultraviolet observations above the earth's atmosphere; infrared observations indicating the association of dust with the envelopes; detection of molecular clouds around the ionized envelopes; and high resolution radio synthesis maps showing the accurate mass distribution of the hot envelopes. The role of Planetary Nebulae in the chemical evolution of the galaxy, and in the physical state of the interstellar medium has also been explored. The topics presented by leading researchers in the field are up-to-date accounts of the observational and theoretical work on Planetary Nebulae. 
PLANETARY NEBULAE OBSERVATIONS AND THEORY 


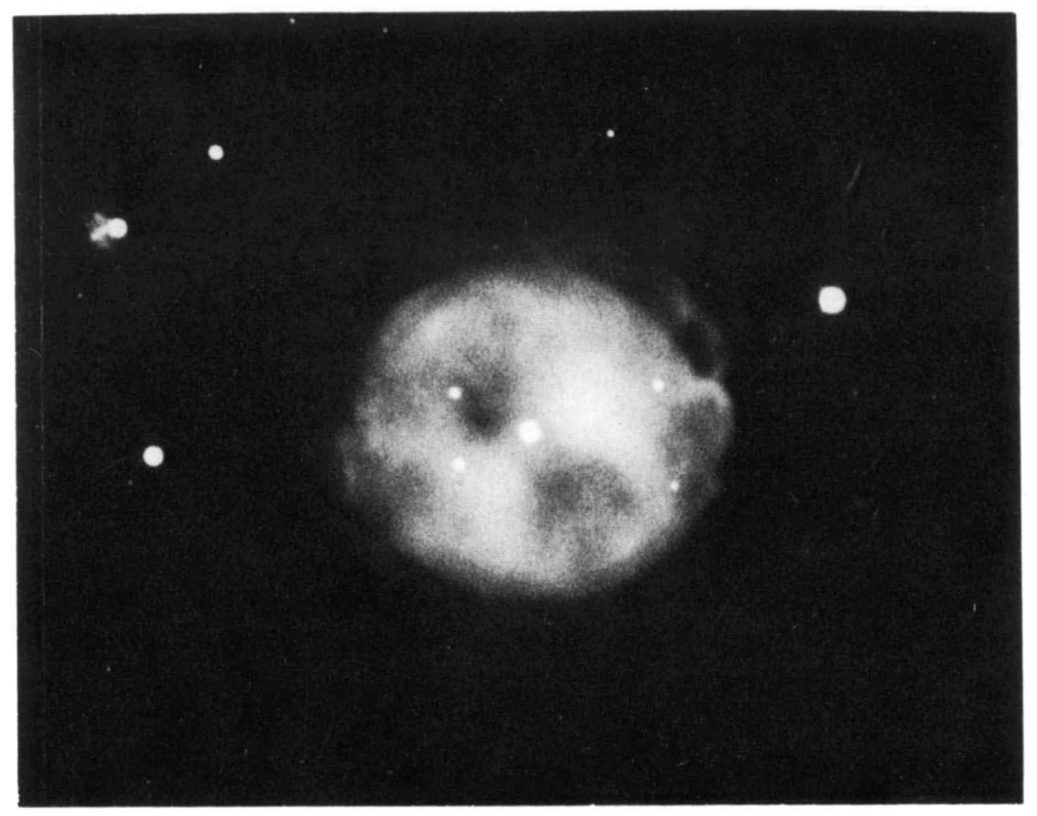

NGC 3587

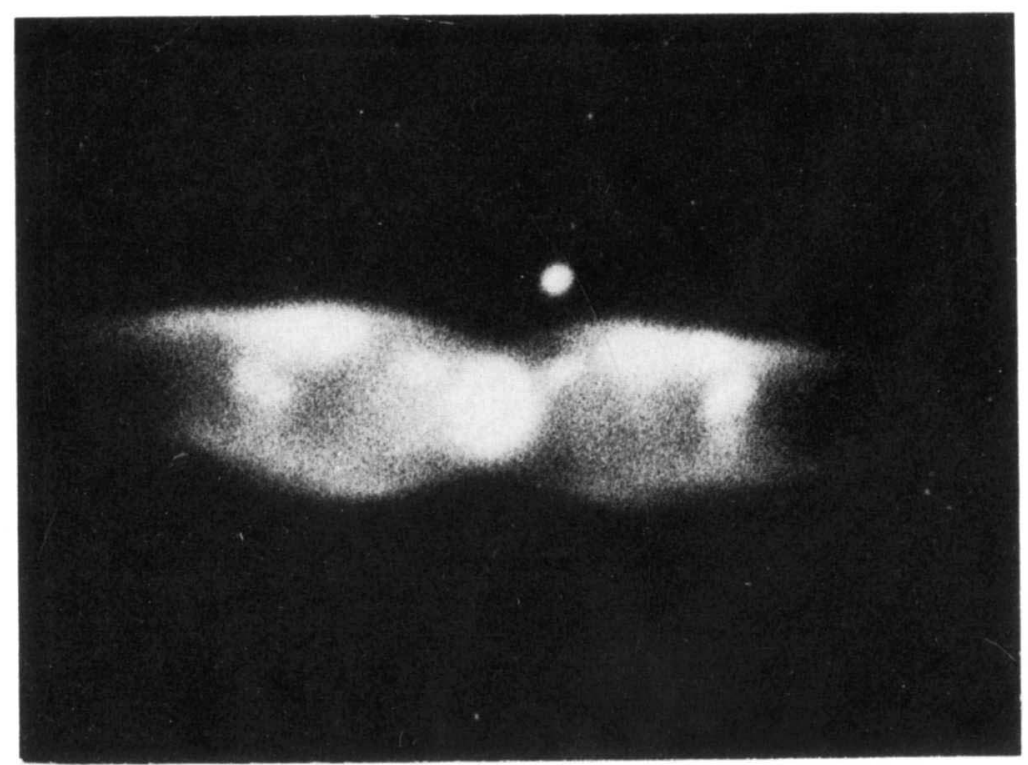

\section{M2-9}


INTERNATIONAL ASTRONOMICAL UNION

UNION ASTRONOMIQUE INTERNATIONALE

S YMPOSIUM No. 76

HELD AT CORNELL UNIVERSITY, ITHACA, NEW YORK, U.S.A.

JUNE 6-10, 1977

\title{
PLANETARY NEBULAE \\ Observations and Theory
}

\author{
EDITED BY \\ YERVANT TERZIAN \\ NAIC, Cornell University
}

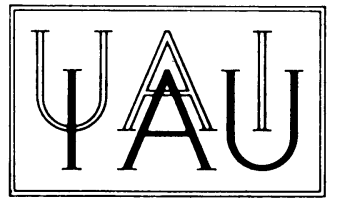

D. REIDEL PUBLISHING COMPANY

DORDRECHT : HOLLAND / BOSTON : U.S.A.

1978 
Library of Congress Cataloging in Publication Data

Planetary Nebulae Symposium, Cornell University, 1977.

Planetary Nebulae.

(Symposium - International Astronomical Union; No. 76)

Bibliography: p.

1. Planetary Nebulae-Congresses. I. Terzian, Yervant, 1939-

II. Title. III. Series: International Astronomical Union. Symposium; No. 76.

QB855.5.P53 $1977 \quad 523.8 \quad 78-4577$

ISBN 90-277-0872-X

ISBN 90-277-0873-8 pbk.

Published on behalf of

the International Astronomical Union

by

D. Reidel Publishing Company, P.O. Box 17, Dordrecht, Holland

All Rights Reserved

Copyright $\odot 1978$ by the International Astronomical Union

Sold and distributed in the U.S.A., Canada, and Mexico

by D. Reidel Publishing Company, Inc.

Lincoln Building, 160 Old Derby Street,

Hingham, Mass. 02043, U.S.A.

No part of the material protected by this copyright notice may be reproduced or utilized in any form or by any means, electronic or mechanical, including photocopying, recording or by any informational storage and retrieval system, without written permission from the publisher

Printed in The Netherlands 
PREFACE

THE ORGANIZING COMMITTEES

LIST OF PARTICIPANTS

SELECTED QUOTATIONS

Yervant Terzian

INTRODUCTORY REMARKS

\section{SESSION I}

THE DISTRIBUTION OF PLANETARY NEBULAE

J.H. Cahn and S.P. Wyatt

STATISTICS - SPATIAL AND VELOCITY DISTRIBUTION OF PLANETARY NEBULAE 3

B. Louise Webster

PLANETARY NEBULAE IN THE MAGELLANIC CLOUDS

Holland C. Ford

PLANETARY NEBULAE IN THE ANDROMEDA GALAXY AND ITS COMPANIONS

William Liller

THE DISTANCE SCALE OF PLANETARY NEBULAE

L. Kohoutek

NEW AND MISCLASSIFIED PLANETARY NEBULAE

\section{SESSION II}

\section{OBSERVATIONS OF PLANETARY NEBULAE}

Joseph S. Miller

ADVANCES IN OPTICAL STUDIES OF PLANETARY NEBULAE

G.A. Gurzadyan

ULTRAVIOLET OBSERVATIONS OF PLANETARY NEBULAE

S.R. Pottasch

ADVANCES IN ULTRAVIOLET OBSERVATIONS

David M. Rank

ADVANCES IN INFRARED OBSERVATIONS OF PLANETARY NEBULAE 
Yervant Terzian

PLANETARY NEBULAE: ADVANCES IN RADIO OBSERVATIONS

ABSTRACTS OF CONTRIBUTED PAPERS

SESSION III

PHYSICAL PROCESSES

M.J. Seaton

ADVANCES IN STUDIES OF PHYSICAL PROCESSES

A. Dalgarno

ATOMIC AND MOLECULAR DATA

J. Patrick Harrington

IONIZATION MODELS OF PLANETARY NEBULAE

ABSTRACTS OF CONTRIBUTED PAPERS

SESSION IV

THE CENTRAL STARS OF PLANETARY NEBULAE

David G. Hummer

ATMOSPHERES OF CENTRAL STARS

Julie H. Lutz

OBSERVATIONS OF CENTRAL STARS

Giora Shaviv

THEORY OF EVOLUTION OF THE CENTRAL STAR

B. Paczyński

THEORY OF EVOLUTION OF CENTRAL STARS OF PLANETARY NEBULAE

\section{SESSION V}

CHEMICAL ABUNDANCES

Manuel Peimbert

CHEMICAL ABUNDANCES IN PLANETARY NEBULAE

Lawrence H. Aller

SOME ASPECTS OF CHEMICAL ABUNDANCE DETERMINATIONS IN PLANETARY NEBULAE 
James B. Kaler

THE ABUNDANCES OF $\mathrm{He}, \mathrm{N}$, $\mathrm{Ne}$, Ar AND $\mathrm{Cl}$

ABSTRACTS OF CONTRIBUTED PAPERS

\section{SESSION VI}

\section{EVOLUTION AND MORPHOLOGY OF PLANETARY NEBULAE}

William G. Mathews

EVOLUTION AND GAS DYNAMICS OF PLANETARY NEBULAE

Eugene R. Capriotti

MORPHOLOGY OF PLANETARY NEBULAE

Bruce Balick

DUST IN PLANETARY NEBULAE: OBSERVATIONAL CONSIDERATIONS

John S. Mathis

DUST IN PLANETARY NEBULAE

\section{SESSION VII}

\section{THE ORIGIN OF PLANETARY NEBULAE}

Ian W. Roxburgh

ORIGIN OF PLANETARY NEBULAE

B. Zuckerman

PROTO-PLANETARY NEBULAE

Nino Panagia

PLANETARY NEBULAE AND RELATED OBJECTS

\section{SESSION VIII}

\section{PLANETARY NEBULAE AND THEIR INFLUENCE ON THE GALAXY}

E.E. Salpeter

PLANETARY NEBULAE AND THE INTERSTELLAR MEDIUM

Beatrice M. Tinsley

PLANETARY NEBULAE AND CHEMICAL EVOLUTION OF THE GALAXY 
D.E. Osterbrock

SYMPOSIUM CONCLUSIONS I

G. Field

SYMPOSIUM CONCLUSIONS II

GENERAL DISCUSSION 